\title{
Validation of TRMM precipitation radar monthly rainfall estimates over Brazil
}

\author{
Sergio H. Franchito, ${ }^{1}$ V. Brahmananda Rao, ${ }^{1}$ Ana C. Vasques, ${ }^{1}$ Clovis M. E. Santo, ${ }^{1}$ \\ and Jorge C. Conforte ${ }^{1}$ \\ Received 8 November 2007; revised 17 September 2008; accepted 31 October 2008; published 23 January 2009.
}

[1] In an attempt to validate the Tropical Rainfall Measuring Mission (TRMM)

precipitation radar (PR) over Brazil, TRMM PR estimates are compared with rain gauge station data from Agência Nacional de Energia Elétrica (ANEEL). The analysis is conducted on a seasonal basis and considers five geographic regions with different precipitation regimes. The results showed that TRMM PR seasonal rainfall is well correlated with ANEEL rainfall (correlation coefficients are significant at the $99 \%$ confidence level) over most of Brazil. The random and systematic errors of TRMM PR are sensitive to seasonal and regional differences. During December to February and March to May, TRMM PR rainfall is reliable over Brazil. In June to August (September to November) TRMM PR estimates are only reliable in the Amazonian and southern (Amazonian and southeastern) regions. In the other regions the relative RMS errors are larger than $50 \%$, indicating that the random errors are high.

Citation: Franchito, S. H., V. B. Rao, A. C. Vasques, C. M. E. Santo, and J. C. Conforte (2009), Validation of TRMM precipitation radar monthly rainfall estimates over Brazil, J. Geophys. Res., 114, D02105, doi:10.1029/2007JD009580.

\section{Introduction}

[2] Seasonal and interannual climate variability in the tropics is mainly determined by the precipitation variability. Brazil is a vast country of continental dimensions with various regimes of precipitation. The northwest of the Amazon basin is characterized by high precipitation rates (of the order of $3000 \mathrm{~mm} \mathrm{a}^{-1}$ ); abundant rain occurs along the coastline of the easternmost part of Brazil $(2000 \mathrm{~mm}$ $\mathrm{a}^{-1}$ ), while some parts of the northeast region receive meager precipitation, including the region known as the "drought polygon", where the annual precipitation can be lower than $400 \mathrm{~mm} \mathrm{a}^{-1}$. The prevailing regimes in southern and southeastern Brazil exhibit a large spatial variability. Precipitation in Brazil also shows a temporal variability, with different rainy seasons for different regions [Rao and Hada, 1990]. These general characteristics are well documented by various textbooks on climatology [e.g., Trewartha, 1961; Ratisbona, 1976; Hastenrath, 1991].

[3] Precipitation variability has a great impact on agricultural productivity and water and energy resources. A better knowledge of climate and climate variability is essential to improve climate prediction as well as to give important information to minimize the impact of adverse climate conditions. There are some studies on climate variability over Brazil that attempt to understand its effects on precipitation regimes. For this purpose reliable information on precipitation is required. The lack of

\footnotetext{
${ }^{1}$ Centro de Previsão de Tempo e Estudos Climáticos, Instituto Nacional de Pesquisas Espaciais, São José dos Campos, Brazil.
}

reliable information about rainfall over Brazil is due to the absence of a dense rain gauge network, mainly over the Amazon region and central Brazil. Satellite-based sensors provide rainfall information on a global scale, but remote-sensing methods used to estimate rainfall from spaceborne instruments are prone to errors. Apart from rain gauges, radar is one of the most powerful tools to detect and quantify rainfall. The launch of the Tropical Rainfall Measuring Mission (TRMM) satellite on 27 November 1997 provides a unique opportunity to examine rainfall characteristics in the tropics in regions that have low density of observations, such as Amazonia and central Brazil. TRMM precipitation radar (PR) is the first spaceborne radar that was designed to capture a more comprehensive structure of rainfall that any previous spaceborne sensor. TRMM PR provides information on the three-dimensional structure of rainfall over the tropics and subtropics [Simpson et al., 1988; Kummerow et al., 2000].

[4] The objective of the present study is to validate TRMM PR data over Brazil on a climatic scale. For this purpose we compare TRMM PR mean seasonal rainfall estimates with rain gauge station data from Agência Nacional de Energia Elétrica (ANEEL). We attempt to investigate the TRMM PR errors compared to ANEEL data for the five geographic Brazilian regions, which are characterized by different precipitation regimes. The validation of TRMM PR data will permit the usage of these data in the future in regions of sparse rain gauge stations. In section 2 we give a brief description of the precipitation data sources used in the study, their inherent errors, and the methodology for the analysis; the regional 


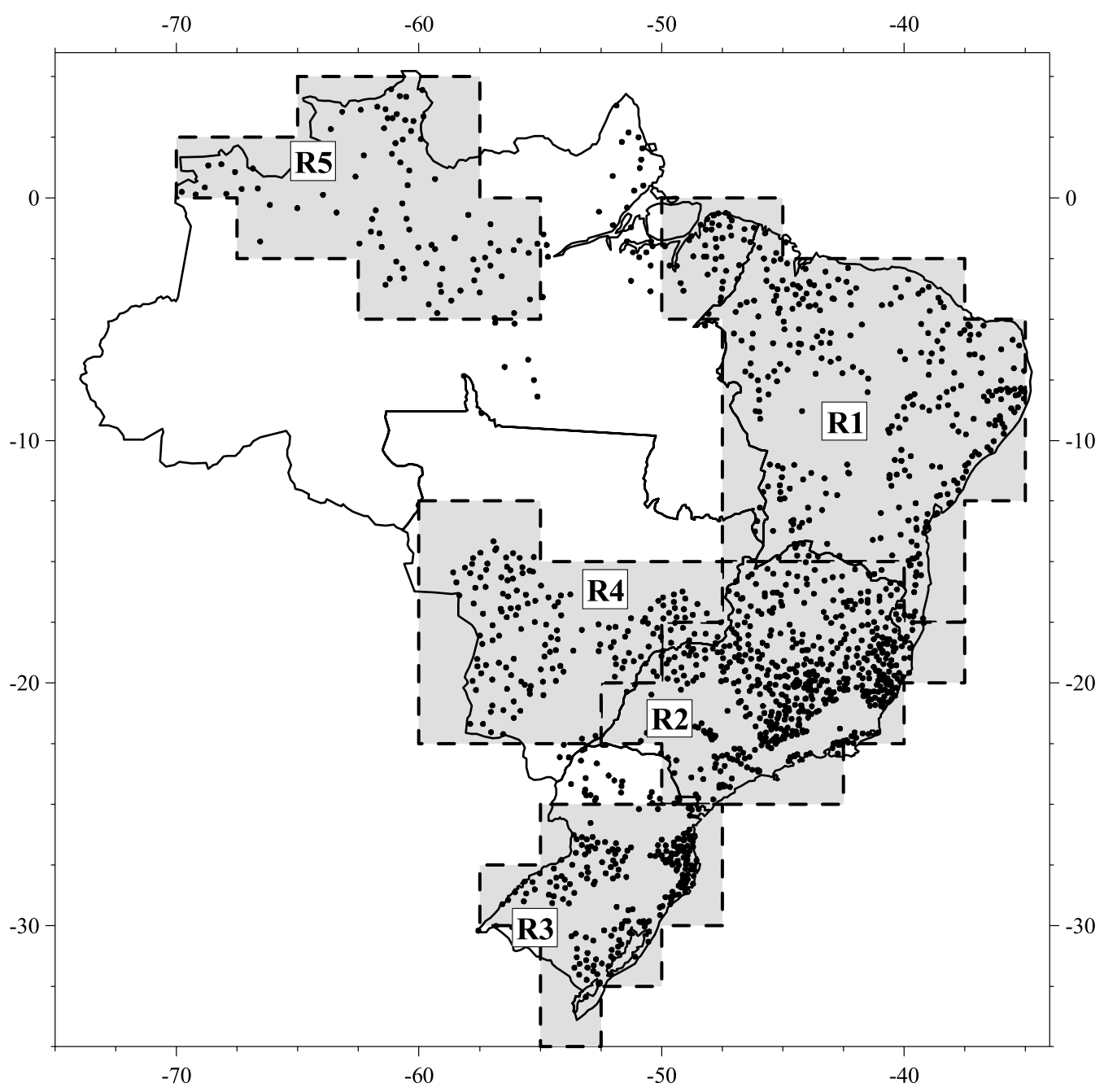

Figure 1. Distribution of the ANEEL stations over the five geographic regions of Brazil. The dashed lines represent the contours of the five selected regions where the $2.5^{\circ} \times 2.5^{\circ}$ ANEEL precipitation data series for the period December 1997 to November 2000 are at least 15 months long.

characteristics of validation are presented in section 3; and section 4 contains the conclusions.

\section{Data and Methodology}

\subsection{Data Sources}

[5] TRMM satellite data are available from December 1997. In the present study we use the accumulated monthly rainfall time series from the TRMM PR level 3 (version 5), which is designated as 3A25G2 (available at ftp://helios.eorc. jaxa.jp/pub/TRMM/L3 data/). These data are available at a high-resolution grid $\left(\overline{0.5^{\circ}} \times 0.5^{\circ}\right.$, latitude by longitude) . The TRMM PR scanning width of about $220 \mathrm{~km}$ measures the rainfall rate from the Earth surface to $20 \mathrm{~km}$ altitude with a horizontal resolution of $4.3 \mathrm{~km}$ at nadir and a vertical resolution of $0.25 \mathrm{~km}$ [Kummerow et al., 1998]. The rainfall rates are calculated from radar reflectivity with corrections for attenuation on the basis of the method given by Iguchi and Meneghini [1994], Iguchi et al. [2000], and Meneghini et al. [2000]. TRMM PR is a Ku band radar with a frequency of $13.8 \mathrm{GHz}$. Since the PR attenuates more at that frequency compared to $\mathrm{C}$ band $(5 \mathrm{~cm})$ and $\mathrm{S}$ band
$(10 \mathrm{~cm})$ radars, the PR algorithm has to use an attenuation correction, which is done using a hybrid technique based on both the Hitchfield-Borden theory and the surface reference technique (SRT). The PR also has issues with nonuniform beam filling (NUBF), resulting in the application of another correction in addition to attenuation for cases of NUBF. This correction is particularly important in convective cases in association with large reflectivity gradients across the PR field of view [Meneghini et al., 2000]. TRMM PR provides information on the three-dimensional structure of rainfall. Besides the rainfall intensity, TRMM PR also contains information on rain types, including stratiform and convective types. Several papers give detailed descriptions of TRMM PR products and applications [Adler et al., 2000; Fu and Liu, 2001, 2003; Fu et al., 2003; Kummerow et al., 2004; Zheng et al., 2004].

[6] Rain gauge station data for Brazil from ANEEL are available for the period 1979-2000 for a large number of stations (Figure 1). The data were checked for consistency (deleting unreasonable values from a climatological viewpoint) and are available at http://hidroweb.ana.gov.br. Although there is a dense concentration of stations in the 

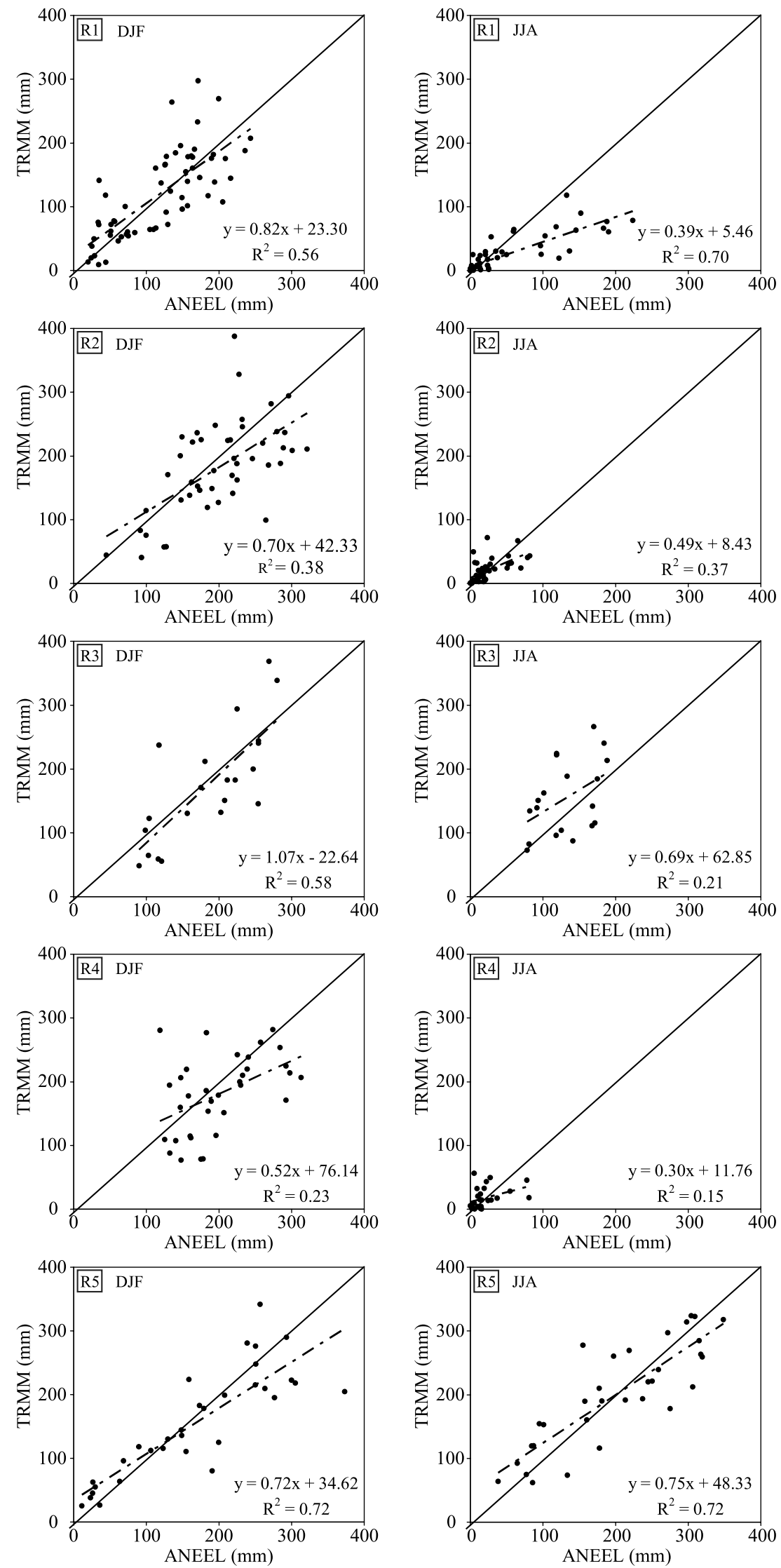

Figure 2. Mean seasonal rainfall from ANEEL versus the rainfall estimates from TRMM PR for the five regions of Figure 1 during (left) DJF and (right) JJA. 


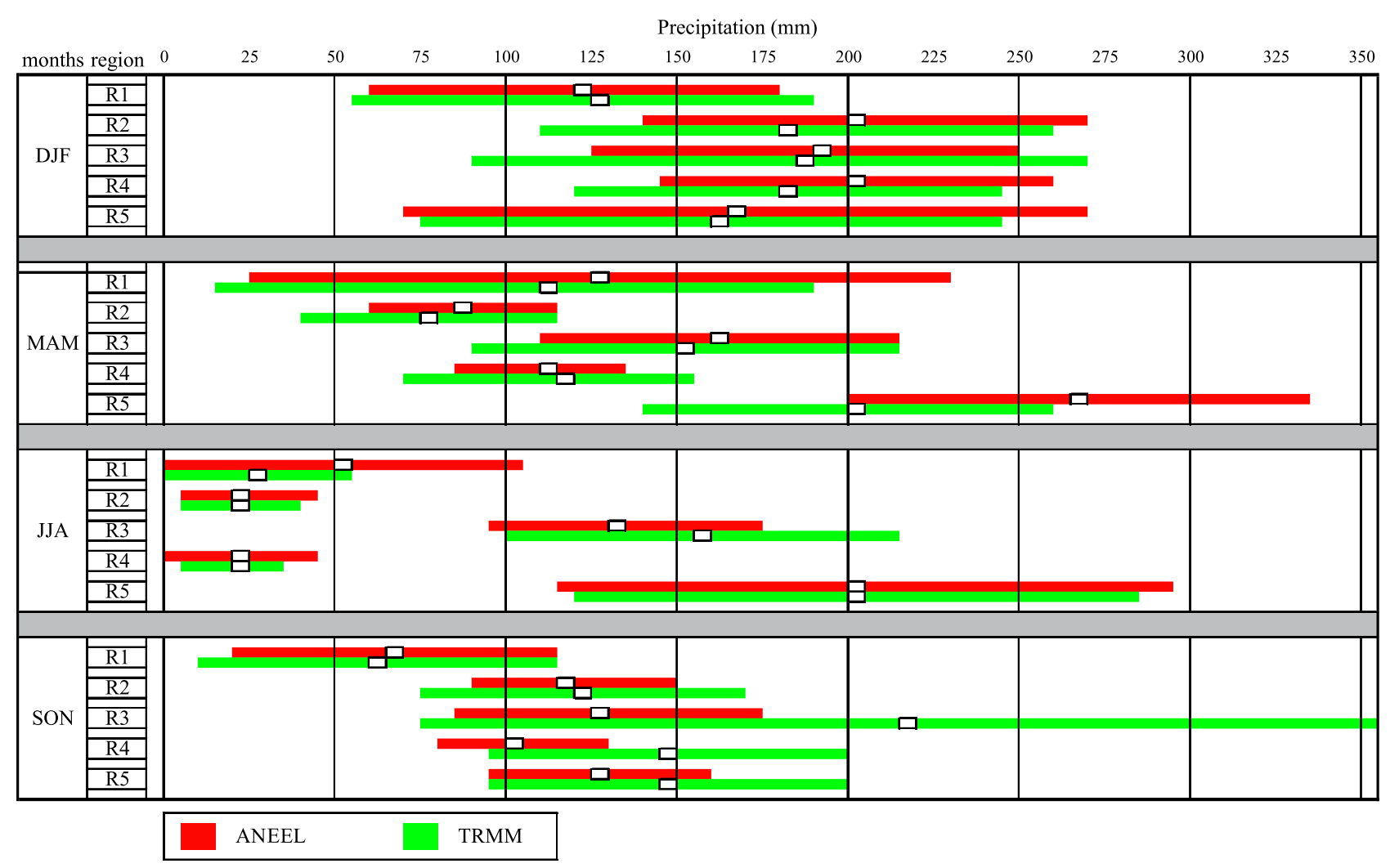

Figure 3. Dispersion intervals of the mean 3 month precipitation over regions $R_{1}, R_{2}, R_{3}, R_{4}$, and $R_{5}$ for the period from December 1997 to November 2000. The intervals around the mean value are $-1 \pm 1$ standard deviation. The small white rectangles represent the mean value of the 3 month precipitation.

northeast, the data are sparse in the north and central regions of Brazil.

[7] In order to obtain spatial homogeneity in the present study, the values of rainfall obtained from TRMM PR are extrapolated to $2.5^{\circ} \times 2.5^{\circ}$ (latitude by longitude) intervals, and the rainfall data from ANEEL are averaged at each $2.5^{\circ} \times 2.5^{\circ}$ grid. Since ANEEL data are available only up to 2000, monthly means for the period December 1997 to November 2000 are considered for the two precipitation data sources. PR's minimum detectable signal during the study period was about $17-18 \mathrm{dbZ}$. Ground radars typically have a much lower minimum detectable signal. The PR consequently has problems observing very light rainfall, especially from high cirrus clouds (e.g., precipitation from anvils). The TRMM satellite underwent a boost in altitude in August 2001 from 350 to $402 \mathrm{~km}$. However, the analysis in the present study only includes data prior to the boost since ANEEL data are only available up to 2000.

\subsection{Data Source Errors}

[8] Monthly rainfall estimates from the TRMM satellite contain errors due to discrete temporal sampling and remote spaceborne rain retrievals. As the TRMM satellite is a low Earth orbiting satellite, its rain sensors sample the regional atmosphere only at discrete time intervals. Sampling frequency is a function of latitude, with more samples collected per month at higher latitudes. Monthly estimates are then generated on the basis of the arithmetical mean of the observations collected at the standard gridding resolution. Many studies have shown that the range of temporal sampling errors is from \pm 8 to $\pm 12 \%$ per month relative to the mean rainfall [Shin and North, 1988; North and Nakamoto, 1989; Bell et al., 1990]. The sampling errors in TRMM monthly estimates are associated with the sampling frequency of the satellite and the coverage area of the sensor. In the case of Brazil, the standard deviations (SDs) (for the period 1998-2005) are less in the northeast region $\left(1-2 \mathrm{~mm} \mathrm{~h}^{-1}\right)$. SD values are around $2-3 \mathrm{~mm} \mathrm{~h}^{-1}$ in the central and southeast regions of Brazil and $3-4 \mathrm{~mm} \mathrm{~h}^{-1}$ in Amazonia. The largest values occur in the southern region (4-5 $\mathrm{mm} \mathrm{h}^{-1}$ ) (see http://daac.gsfc.nasa.gov/precipitation/ TRMM_README/TRMM_3A25_readme.shtml). Another error source for the TRMM PR is related to the attenuation correction, especially where the SRT is not as reliable (the SRT works best over the ocean where there is a relatively stable and homogeneous surface). The nonuniform rain distribution within the radar resolution cell might become a large source of error when the attenuation is severe. Details of the errors due to the attenuation issue are given by Iguchi et al. [2000] and Meneghini et al. [2000].

[9] TRMM PR and TRMM Microwave Imager (TMI) suffer from regional sampling errors. Since the PR has a narrower swath width $(220 \mathrm{~km})$ compared to the TMI (758.5 km) [Kummerow et al., 1998], the expected sampling error is greater (around 30\%). However, the TMI retrieval error exceeds retrieval error for PR by about a factor of 2 [Fisher, 2007]. Because of their larger swath width, the use of TMI data generally creates a superior overview of the synoptic rainfall events but comes at the expense of a 


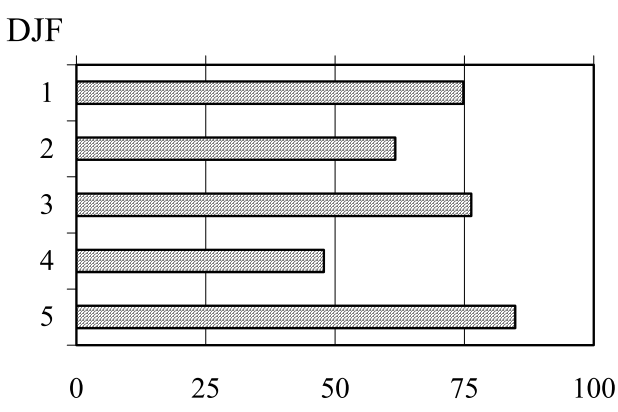

MAM

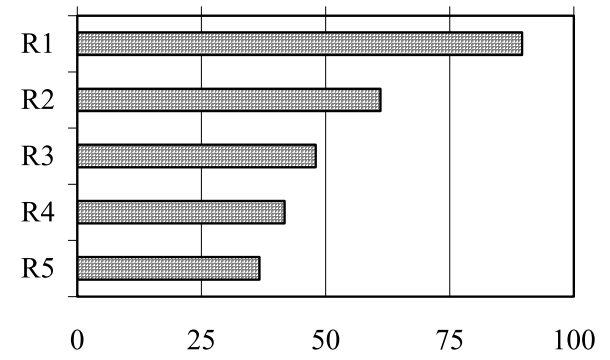

JJA

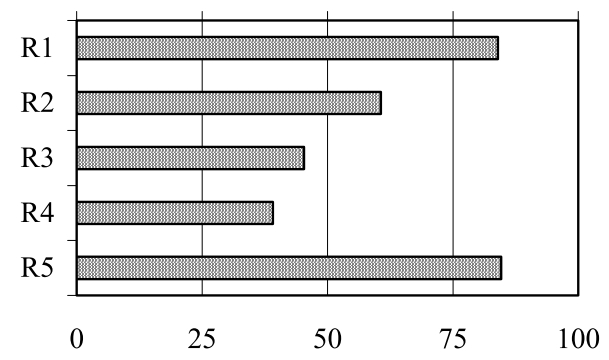

SON

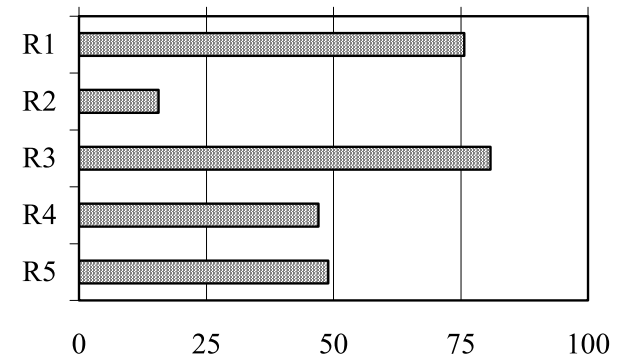

(a)

correlation $(\%)$
DJF

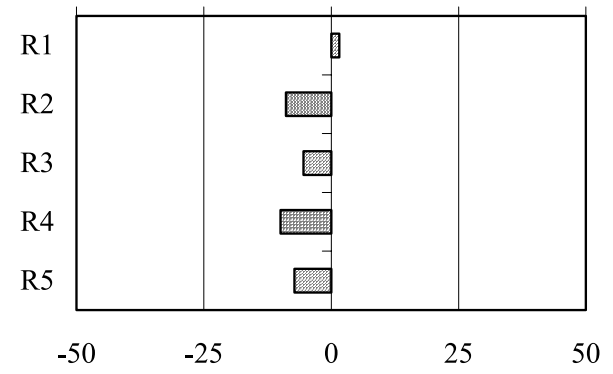

MAM

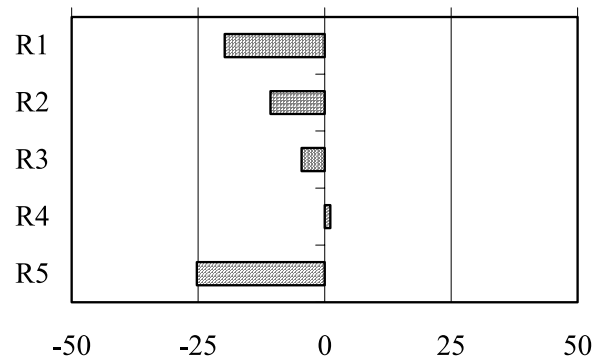

JJA

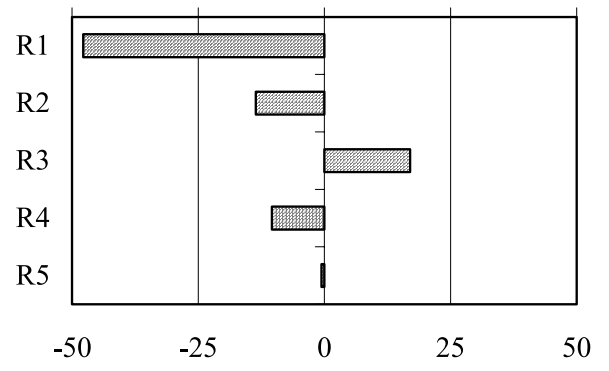

SON

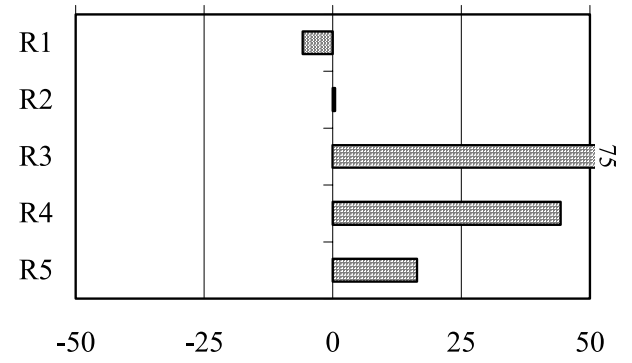

(b)

bias ( \%)

Figure 4. Seasonal variations of (a) correlation coefficient obtained between TRMM PR rainfall estimates and ANEEL rain gauge data and (b) \% MBE for the five regions of Figure 1.

decrease in the resolution [Stano et al., 2002]. PR produces more reliable estimates of precipitation near the surface than passive microwave does. The use of radar for the measurement of precipitation allows the detection of rain occurring at brightness temperatures greater than those used in passive techniques. Moreover, much of the light and heavy rainfall is missed by passive microwaves because of its small scale and/or its nature (for example, "warm rain"). In both cases $\mathrm{PR}$ is more able to measure and quantify the precipitation than TMI [De Angelis et al., 2004].
[10] Compared to TRMM PR estimates, rain gauge measurements are more or less continuous in time but with very small coverage in area, whereas radar views irregularly shaped volumes of the atmosphere at frequent but noncontinuous intervals of time. Rain gauges are subject to systematic errors related to losses due to the aerodynamic effects. For example, gauges have a tendency to underestimate rainfall in high-winds conditions (see http://radarmet.atmos. colostate.edu/ $\sim$ snesbitt/research/nesbitt_jampaper.pdf). 
Table 1. Mean Seasonal Values of the Correlation Coefficient, Relative Root-Mean-Square Error, Relative Mean Bias Error, and Relative Absolute Error for the Five Regions of Brazil in Figure 1 for TRMM PR Compared to ANEEL

\begin{tabular}{|c|c|c|c|c|c|}
\hline Region & $\begin{array}{c}\text { Number of } \\
\text { Data } \\
\text { Points }\end{array}$ & $\begin{array}{c}\text { Correlation } \\
\text { Value }(\%)\end{array}$ & $\begin{array}{c}\text { Relative } \\
\text { Root } \\
\text { Mean } \\
\text { Square } \\
\text { Error }(\%) \\
\end{array}$ & $\begin{array}{c}\text { Relative } \\
\text { Mean } \\
\text { Bias } \\
\text { Error }(\%) \\
\end{array}$ & $\begin{array}{c}\text { Relative } \\
\text { Mean } \\
\text { Absolute } \\
\text { Error (\%) }\end{array}$ \\
\hline \multicolumn{6}{|c|}{ December to February } \\
\hline R1 & 60 & 74.8 & 39.4 & 1.6 & 31.2 \\
\hline R2 & 46 & 61.6 & 31.5 & -8.9 & 25.2 \\
\hline R3 & 21 & 76.3 & 31.2 & -5.4 & 26.0 \\
\hline R4 & 34 & 47.8 & 31.1 & -9.9 & 24.7 \\
\hline R5 & 32 & 84.8 & 31.9 & -7.2 & 22.1 \\
\hline \multicolumn{6}{|c|}{ March to May } \\
\hline R1 & 60 & 89.6 & 42.3 & -19.8 & 30.6 \\
\hline R2 & 45 & 61.1 & 37.8 & -10.7 & 28.1 \\
\hline R3 & 19 & $48.0^{\mathrm{a}}$ & $36.2^{\mathrm{a}}$ & $-4.5^{\mathrm{a}}$ & $29.4^{\mathrm{a}}$ \\
\hline R4 & 31 & $41.8^{\mathrm{a}}$ & $36.8^{\mathrm{a}}$ & $1.1^{\mathrm{a}}$ & $28.0^{\mathrm{a}}$ \\
\hline R5 & 31 & $36.7^{\mathrm{a}}$ & $36.7^{\mathrm{a}}$ & $-25.2^{\mathrm{a}}$ & $29.1^{\mathrm{a}}$ \\
\hline \multicolumn{6}{|c|}{ June to August } \\
\hline R1 & 59 & 84.0 & 104.8 & -47.8 & 55.6 \\
\hline R2 & 43 & 60.6 & 79.8 & -13.6 & 51.8 \\
\hline R3 & 19 & $45.3^{\mathrm{b}}$ & $42.8^{\mathrm{b}}$ & $17.0^{\mathrm{b}}$ & $36.3^{\mathrm{b}}$ \\
\hline R4 & 26 & $39.1^{\mathrm{a}}$ & $106.5^{\mathrm{a}}$ & $-10.4^{\mathrm{a}}$ & $75.4^{\mathrm{a}}$ \\
\hline R5 & 32 & 84.6 & 23.8 & -0.6 & 19.7 \\
\hline \multicolumn{6}{|c|}{ September to November } \\
\hline R1 & 59 & 75.7 & 54.8 & -5.9 & 39.0 \\
\hline R2 & 43 & $15.6^{\mathrm{b}}$ & $44.2^{\mathrm{b}}$ & $0.5^{\mathrm{b}}$ & $34.7^{\mathrm{b}}$ \\
\hline R3 & 19 & 80.9 & 118.1 & 75.4 & 87.3 \\
\hline R4 & 26 & $47.0^{\mathrm{a}}$ & $64.5^{\mathrm{a}}$ & $44.3^{\mathrm{a}}$ & $52.6^{\mathrm{a}}$ \\
\hline R5 & 32 & 49.0 & 40.6 & 16.4 & 34.6 \\
\hline
\end{tabular}

${ }^{\mathrm{a}}$ The region and period where the CC is not significant at the $99 \%$ confidence level by a two-tailed Student's $t$ test.

${ }^{\mathrm{b}}$ The region and period where the CC is not significant at the $95 \%$ confidence level by a two-tailed Student's $t$ test.

\subsection{Processing Methods}

[11] The data coverage for this study is for 3 years (December 1997 to November 2000). The seasonal analyses are based on 3 month averages: December to February (DJF), March to May (MAM), June to August (JJA), and September to November (SON). We concentrate our analyses on the five geographic regions of Brazil: the north, northeast, central, southeast, and south, as shown in Figure 1. A tropical rain forest climate lies in the northern region; the northeastern and southern regions are characterized by a semiarid and temperate climate, respectively; savanna and cerrado are found in central Brazil, while southeastern Brazil is a transition region between semiarid and temperate climates. The ANEEL ground stations are distributed very heterogeneously in the country, as shown in Figure 1. On the basis of the location of the ANEEL stations and the available rainfall data measured during the period December 1997 to November 2000, five areas were chosen inside the five geographic regions $\left(\mathrm{R}_{1}, \mathrm{R}_{2}, \mathrm{R}_{3}, \mathrm{R}_{4}\right.$, and $\mathrm{R}_{5}$ in Figure 1$)$. The averaged precipitation data series for each $2.5^{\circ} \times 2.5^{\circ}$ grid cell inside these areas are at least 15 months long. The criteria used for averaging the data over a $2.5^{\circ} \times 2.5^{\circ}$ grid cell are based on the number of the rain gauges for ANEEL and on the number of data at $0.5^{\circ} \times 0.5^{\circ}$ (latitude by longitude) for TRMM PR. For each region, mean bias error
(MBE), absolute error, and root-mean-square error (RMSE) are calculated for TRMM PR rainfall estimates. The reference is to ANEEL rain gauge data. The mean bias corresponds to the difference between the mean of rainfall estimates (TRMM PR) and the mean of observations (ANEEL). The root-mean-square error corresponds to the square root of the average of the squared differences between the rainfall estimates and the observed rainfall. The mean absolute error is the average of the absolute differences between rainfall estimates and observations. It is a more robust measure of the accuracy of rainfall estimates than mean square error that is sensitive to large rainfall estimates errors (see http://www.nws.noaa.gov/oh/rfcdev/ docs/Glossary_Verification_Metrics.pdf).

[12] The percentage or relative MBE (\% MBE), relative absolute error ( $\%$ AE), and relative RMSE (\% RMSE) are also calculated for each region. In the analysis, $\% \mathrm{MBE}$ and $\%$ RMSE are used to ascertain the systematic and random components of the error in the TRMM PR data, respectively [Adeyewa and Nakamura, 2003]. The parameter \% RMSE is used to evaluate the reliability of each data source in the different regions of Brazil. When the RMSE of a rainfall estimate is less than $50 \%$ of the measured rainfall amount, that estimate is reliable. On the other hand, when the RMSE is equal to or higher than $50 \%$ of the magnitude of the reference rainfall, the estimate is considered unreliable for the region and particular season. The errors are calculated only when the data are available at a particular grid point for both data sources. Scattergrams of mean seasonal precipitation of ANEEL rain gauge versus TRMM PR rainfall estimates are plotted in Figure 2 for the five Brazilian regions.

\section{Results}

[13] In Figure 2 the mean seasonal (DJF and JJA) rainfall from ANEEL is plotted against the rainfall estimates from TRMM PR for the five regions $\left(R_{1}, R_{2}, R_{3}, R_{4}\right.$, and $\left.R_{5}\right)$ of Figure 1. The best agreements between TRMM PR and ANEEL are obtained for the tropical rain forest $\left(R_{5}\right)$ in DJF and for the semiarid $\left(R_{1}\right)$ and tropical rain forest $\left(R_{5}\right)$ in JJA, and the poorest agreement occurs in the savanna and cerrado regions $\left(\mathrm{R}_{4}\right)$ for both DJF and JJA. Figure 3 shows the dispersion intervals of the mean 3 month precipitation over regions $R_{1}, R_{2}, R_{3}, R_{4}$, and $R_{5}$ for the period from December 1997 to November 2000. As can be seen, there is a good agreement between the mean precipitation values and their dispersion around the mean for the two data sources, mainly for DJF and JJA. During MAM, over region $R_{5}$, and $S O N$, over region $R_{3}$, the TRMM PR mean and dispersion values are very different from ANEEL values. Over region $R_{5}$, the mean precipitation is underestimated, although the dispersion is about the same compared to ANEEL, and over region $\mathrm{R}_{3}$, the mean and dispersion are overestimated. During SON, the TRMM estimates show mean and dispersion values larger than ANEEL values over all the regions except $R_{1}$.

[14] The correlation coefficients (CCs) between TRMM PR and ANEEL for each season are shown in Figure $4 a$ and Table 1. It can be noted that seasonal values of CC between TRMM PR and ANEEL are high (significant at the 99\% confidence level by a two-tailed Student's $t$ test) for most of 

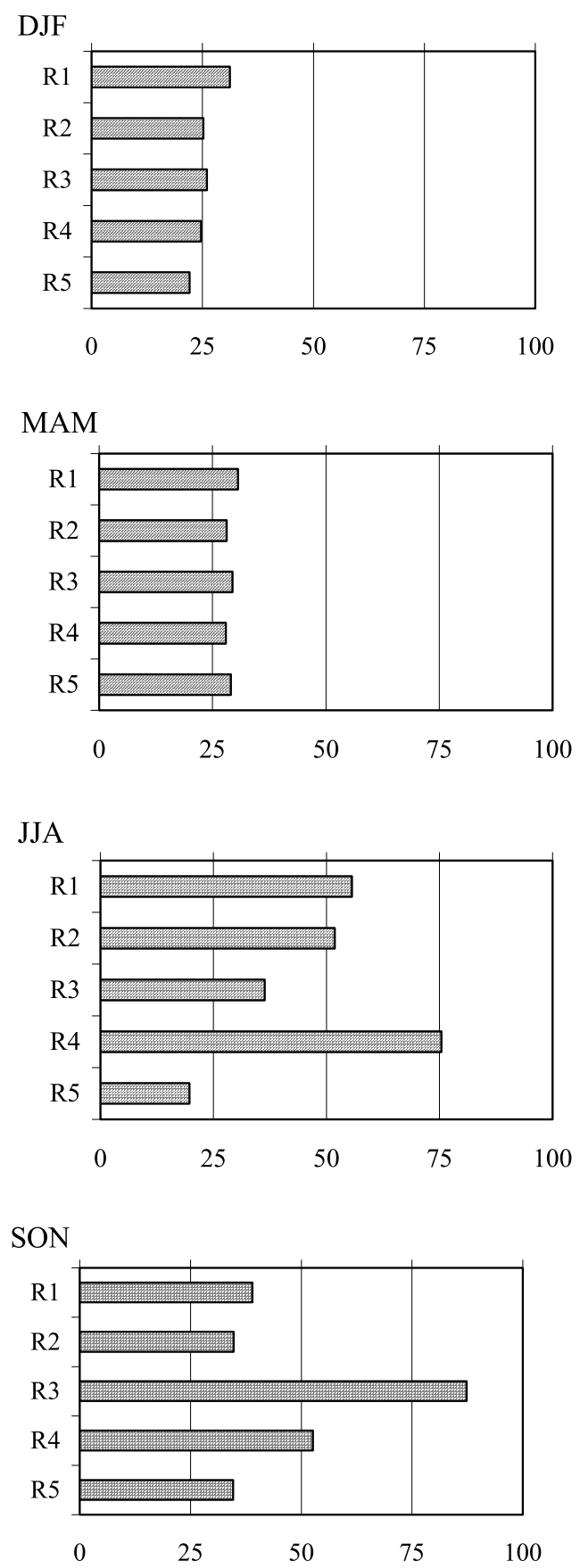

(a)

absolute error (\%)
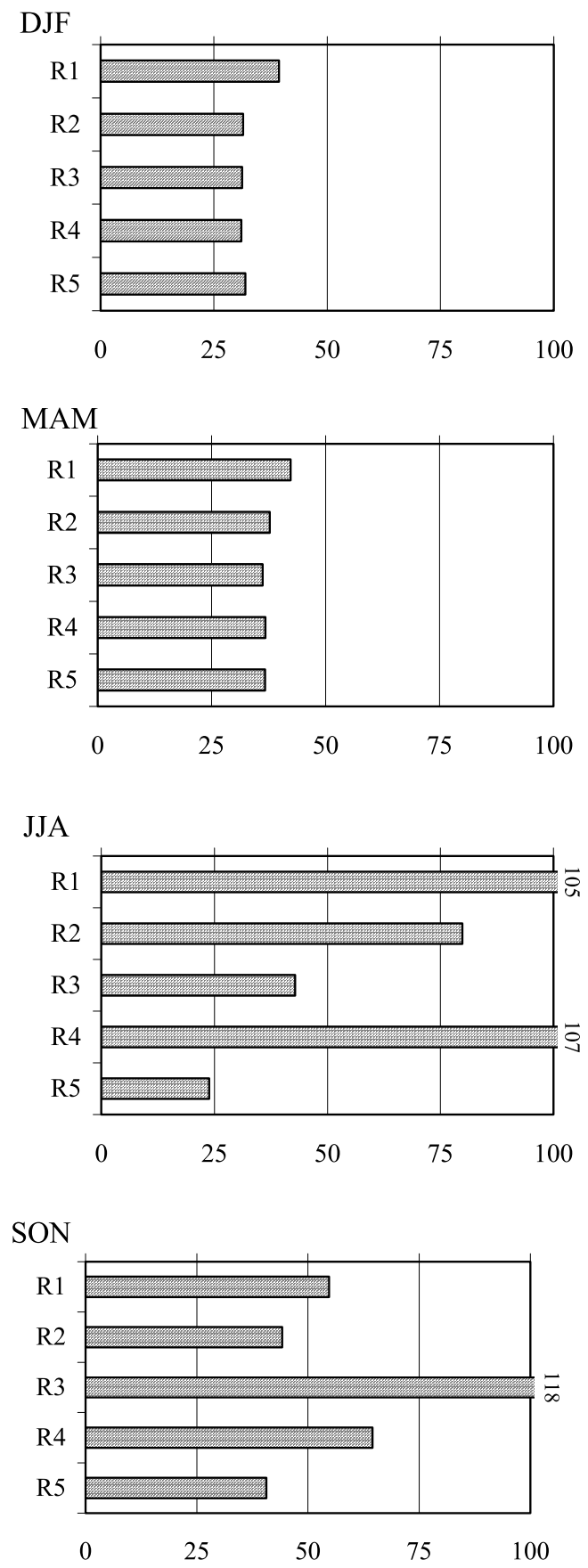

(b)

rmse (\%)

Figure 5. Seasonal variations of the (a) relative (\%) absolute error and (b) $\%$ RMSE for TRMM PR data for the five regions of Figure 1.

the regions. The highest values occur in the semiarid region $\left(\mathrm{R}_{1}\right)$ during MAM (89.6\%) and JJA (84\%) and during DJF and JJA $(>84 \%)$ in the tropical rain forest $\left(\mathrm{R}_{5}\right)$. The values of $\mathrm{CC}$ are not significant only in the temperate region $\left(\mathrm{R}_{3}\right)$ during JJA and in the transition region $\left(\mathrm{R}_{2}\right)$ during SON. Figure $4 \mathrm{~b}$ shows the seasonal variation of the $\%$ MBE for the five regions of Figure 1 for TRMM PR. As can be seen, the \% MBE for TRMM PR is negative in most seasons for all regions. Positive \% MBE is obtained for the temperate region $\left(\mathrm{R}_{3}\right)$ in JJA and SON and for the savanna and cerrado
$\left(\mathrm{R}_{4}\right)$ and tropical rain forest $\left(\mathrm{R}_{5}\right)$ regions in $\mathrm{SON}$. The absolute value of the \% MBE for TRMM PR is, in general, lower than $25 \%$. The highest value of the \% MBE (75\%) occurs in the temperate region $\left(\mathrm{R}_{3}\right)$ in SON.

[15] Figure 5a shows the seasonal variation of the $\% \mathrm{AE}$ for the five regions of Figure 1 for TRMM PR. As can be noted, the \% AE for TRMM PR is, in general, lower than $50 \%$ in most seasons for all regions. The lowest values occur in DJF and MAM for the five regions, while the highest values occur in the savanna and cerrado region $\left(R_{4}\right)$ 
Table 2. Seasonal Values of the Mean Precipitation, Mean Bias Error, and Root-Mean-Square Error in the Five Regions of Figure $1^{\mathrm{a}}$

\begin{tabular}{|c|c|c|c|c|c|}
\hline & \multicolumn{5}{|c|}{ Region } \\
\hline & $\mathrm{R}_{1}$ & $\mathrm{R}_{2}$ & $\mathrm{R}_{3}$ & $\mathrm{R}_{4}$ & $\mathrm{R}_{5}$ \\
\hline \multicolumn{6}{|c|}{ December to February } \\
\hline Mean precipitation & 117.4 & 200.3 & 185.4 & 200.9 & 167.3 \\
\hline MBE & 1.8 & -17.8 & -10.1 & -20.0 & -12.1 \\
\hline RMSE & 46.2 & 63.0 & 57.9 & 62.5 & 53.5 \\
\hline \multicolumn{6}{|c|}{ March to May } \\
\hline Mean precipitation & 124.8 & 84.7 & 158.7 & 107.7 & 264.5 \\
\hline MBE & -24.7 & -9.0 & -7.2 & 1.2 & -66.7 \\
\hline RMSE & 52.8 & 32.0 & 57.4 & 39.6 & 97.1 \\
\hline \multicolumn{6}{|c|}{ June to August } \\
\hline Mean precipitation & 42.1 & 22.7 & 132.0 & 19.8 & 202.0 \\
\hline MBE & -20.1 & -3.1 & 22.4 & -2.1 & -1.2 \\
\hline RMSE & 44.1 & 18.1 & 56.6 & 21.1 & 48.1 \\
\hline \multicolumn{6}{|c|}{ September to November } \\
\hline Mean precipitation & 64.5 & 118.9 & 129.2 & 100.6 & 123.8 \\
\hline MBE & -3.8 & 0.6 & 97.4 & 44.5 & 20.3 \\
\hline RMSE & 35.3 & 52.6 & 152.5 & 64.9 & 50.3 \\
\hline
\end{tabular}

${ }^{\mathrm{a}}$ Mean precipitation values are given in $\mathrm{mm}$ and come from ANEEL. Bias and RMSE come from TRMM PR and are given in \%.

in JJA and SON and in the temperate region $\left(\mathrm{R}_{3}\right)$ in SON. Figure $5 \mathrm{~b}$ shows the seasonal variation of the $\%$ RMSE for the five regions of Figure 1 for TRMM PR. As can be seen, the $\%$ RMSE values for TRMM PR are $\leq 39 \%$ for the all the regions in DJF and MAM. However, in JJA they are higher than $50 \%$ in the semiarid $\left(\mathrm{R}_{1}\right)$, transition $\left(\mathrm{R}_{2}\right)$, and savanna and cerrado $\left(\mathrm{R}_{4}\right)$ regions. In SON, values of $\%$ RMSE are also higher than $50 \%$ in the semiarid $\left(R_{1}\right)$, temperate $\left(R_{3}\right)$, and savanna and cerrado $\left(\mathrm{R}_{4}\right)$ regions. The mean seasonal values of the CC, $\% \mathrm{MBE}, \% \mathrm{AE}$, and $\% \mathrm{RMSE}$ for the five regions of Figure 1 for TRMM PR are summarized in Table 1.

[16] The results in section 3 showed that the seasonal CC values between TRMM PR and ANEEL rainfall are high (significant at the $99 \%$ confidence level) in most of the five regions of Figure 1. The results indicated that the precipitation product of TRMM PR is reliable for the five regions of Figure 1 in DJF and MAM since the values of the \% RMSE and \% MBE are low in these areas. In JJA the TRMM PR estimates are only reliable in the temperate $\left(\mathrm{R}_{3}\right)$ and tropical rain forest $\left(\mathrm{R}_{5}\right)$ regions. In the other regions the TRMM PR precipitation product is unreliable because the inherent error in its estimation generally exceeds $50 \%$ of the reference rainfall amount ( $\%$ RMSE $>50 \%)$. Thus, one can conclude that the random error is high in these regions during this period. In SON the TRMM PR rainfall estimates are only reliable in the transition region $\left(\mathrm{R}_{2}\right)$ and in the tropical rain forest $\left(R_{5}\right)$. In particular, in the temperate $\left(R_{3}\right)$ and savanna and cerrado region $\left(\mathrm{R}_{4}\right)$ both the \% RMSE and $\% \mathrm{MBE}$ are high. It therefore can be concluded that in this season the random and systematic errors are high in these regions. Thus, TRMM PR rainfall estimates are reliable in some regions and seasons and not in others. In general, the TRMM PR is reliable where the mean precipitation is high. From Table 2 it can be seen that in DJF and MAM the mean precipitation is high in all the regions, which leads to low values of \% MBE and \% RMSE. The period JJA corresponds to the dry season over most of Brazil. Although the values of the bias and RMSE are low, in general, the mean precipitation is also low, so the \% MBE and \% RMSE are high. However, in the temperate region $\left(\mathrm{R}_{3}\right)$ and in the tropical rain forest region $\left(\mathrm{R}_{5}\right)$ the mean precipitation is high, leading to low values of \% MBE and \% RMSE, and consequently, TRMM PR is reliable in these regions. The period SON corresponds to the onset of the rainy season over central and southeastern Brazil. The mean precipitation is high in the transition region $\left(\mathrm{R}_{2}\right)$ (southeastern Brazil), which leads to low values of the \% MBE and \% RMSE. However, in the savanna and cerrado region $\left(\mathrm{R}_{4}\right)$ (which is in central Brazil) although the mean precipitation is high, the values of the bias and RMSE are also high, so TRMM $\mathrm{PR}$ is not reliable. This also occurs in the temperate region $\left(\mathrm{R}_{3}\right)$. Thus, the reliability of TRMM PR depends on both the seasonal and regional values of the RMSE and the mean precipitation.

\section{Conclusions}

[17] In this study the potentialities and limitations of TRMM PR data over Brazil were evaluated, comparing the characteristics in these data with rain gauge station data from ANEEL. The precipitation data for a 3 year period (December 1997 to November 2000) were used. The analysis was conducted on a seasonal basis and considered five Brazilian geographic regions, which have different climatic characteristics and precipitation regimes. The CC, mean bias errors, absolute errors, and RMSE for TRMM PR with respect to ANEEL rain gauge data were computed.

[18] The results showed that the TRMM PR seasonal rainfall is well correlated with ANEEL rainfall $(\mathrm{CC}$ is significant at the $99 \%$ confidence level by a two-tailed Student's $t$ test) in most of the five regions. However, the random and systematic errors are sensitive to seasonal and regional differences. During DJF and MAM the precipitation product of TRMM PR is reliable for the five regions of Brazil. In JJA the TRMM PR estimates are only reliable in the Amazonian and southern regions. In the other regions the TRMM PR precipitation product is less reliable because the inherent error in its estimation generally exceeds $50 \%$ of the reference rainfall amount (\% RMSE > 50\%). Thus, one can conclude that the random error is high in these regions during this period. During SON the TRMM PR rainfall estimates are only accurate in the Amazonian and southeastern regions. In the particular cases of the southern and central regions the random and systematic errors are high. The present systematic study of validation will permit usage of remotely sensed rainfall data in regions of sparse rain gauge stations, knowing the potentialities and limitations of satellite rainfall estimates.

[19] Acknowledgments. The third author was supported by Fundação de Amparo à Pesquisa do Estado de São Paulo. Thanks are due to the reviewers for the useful suggestions.

\section{References}

Adeyewa, Z. D., and K. Nakamura (2003), Validation of TRMM radar rainfall data over the major climatic regions in Africa, J. Appl. Meteorol. Climatol., 42, 331-347, doi:10.1175/1520-0450(2003)042<0331: VOTRRD $>2.0 . \mathrm{CO} ; 2$.

Adler, R. F., G. J. Huffman, D. T. Bolvin, S. Curtis, and E. J. Nelkin (2000), Tropical rainfall distribution determined using TRMM combined with other satellite and rain gauge information, J. Appl. Meteorol., 39, 2007-2023, doi:10.1175/1520-0450(2001)040<2007:TRDDUT>2.0.CO;2. 
Bell, T. L., A. Abdullah, R. L. Martin, and G. North (1990), Sampling errors for satellite-derived tropical rainfall: Monte Carlo study using a space-time stochastic model, J. Geophys. Res., 95, 2195-2205, doi:10.1029/JD095iD03p02195.

De Angelis, C. F., G. R. McGregor, and C. Kidd (2004), A 3 year climatology of rainfall characteristics over tropical and subtropical South America based on Tropical Rainfall Measuring Mission precipitation radar data, Int. J. Climatol., 24, 385-399, doi:10.1002/joc.998.

Fisher, B. L. (2007), Statistical error decomposition of regional-scale climatological precipitation estimates from the Tropical Rainfall Measuring Mission (TRMM), J. Appl. Meteorol. Climatol., 46, 791-813, doi:10.1175/JAM2497.1.

$\mathrm{Fu}$, Y., and G. Liu (2001), The variability of tropical precipitation profiles and its impact on microwave brightness temperatures as inferred from TRMM data, J. Appl. Meteorol., 40, 2130-2143, doi:10.1175/15200450(2001)040<2130:TVOTPP $>2.0$.CO; 2 .

Fu, Y., and G. Liu (2003), Precipitation characteristics in mid-latitude east Asia as observed by TRMM PR and TMI, J. Meteorol. Soc. Jpn., 81, $1353-1367$, doi:10.2151/jmsj.81.1353.

Fu, Y., Y. H. Lin, G. Liu, and Q. Wang (2003), Seasonal characteristics of precipitation in 1998 over east Asia as derived from TRMM PR, Adv. Atmos. Sci., 20, 511-529, doi:10.1007/BF02915495.

Hastenrath, S. (1991), Climate Dynamics of the Tropics, 488 pp., Kluwer Acad., Dordrecht, Netherlands.

Iguchi, T., and R. Meneghini (1994), Intercomparison of single-frequency methods for retrieving a vertical rain profile from airborne or space radar data, J. Atmos. Oceanic Technol., 11, 1507-1516, doi:10.1175/15200426(1994)011<1507:IOSFMF>2.0.CO;2.

Iguchi, T., R. Meneghini, J. Awaka, and K. Okamoto (2000), Rain profiling algorithm for the TRMM precipitation radar, J. Appl. Meteorol., 39 , 2038-2052, doi:10.1175/1520-0450(2001)040<2038:RPAFTT $>2.0$. $\mathrm{CO} ; 2$.

Kummerow, C., W. Barnes, T. Kozu, J. Shiue, and J. Simpson (1988), The Tropical Rainfall Measuring Mission (TRMM) sensor package, J. Atmos. Oceanic Technol., 15, 809-817, doi:10.1175/1520-0426(1998) 015<0809:TTRMMT>2.0.CO;2.

Kummerow, C., et al. (2000), The status of the Tropical Rainfall Measuring Mission (TRMM) after two years in orbit, J. Appl. Meteorol., 39, 19651982, doi:10.1175/1520-0450(2001)040<1965:TSOTTR>2.0.CO;2.
Kummerow, C., P. Poyner, W. Berg, and J. Thomas-Stahle (2004), The effects of rainfall inhomogeneity on climate variability of rainfall estimated from passive microwave sensors, J. Atmos. Oceanic Technol., 21, 624-638, doi:10.1175/1520-0426(2004)021<0624:TEORIO>2.0.CO;2.

Meneghini, R., T. Iguchi, T. Kozo, L. Liao, K. Okamoto, J. A. Jones, and J. Kwiatkowski (2000), Use of the surface reference technique for path attenuation estimates from the TRMM precipitation radar, J. Appl. Meteorol. 39, 2053-2070, doi:10.1175/1520-0450(2001)040<2053:UOTSRT>2.0. $\mathrm{CO} ; 2$.

North, G. R., and S. Nakamoto (1989), Formalism for comparing rain estimation designs, J. Atmos. Oceanic Technol., 6, 985-992, doi:10.1175/ 1520-0426(1989)006<0985:FFCRED>2.0.CO;2.

Rao, V. B., and K. Hada (1990), Characteristics of rainfall over Brazil: Annual variations and connections with the Southern Oscillation, Theor. Appl. Climatol., 42, 81-91, doi:10.1007/BF00868215.

Ratisbona, C. R. (1976), The climate of Brazil, in Climates of Central and South America, World Surv. Climatol., vol. 12, edited by W. Schwerdtfeger and H. E. Landsberg, pp. 219-293, Elsevier, Amsterdam.

Shin, K., and G. R. North (1988), Sampling error study for rainfall estimate by satellite using a stochastic model, J. Appl. Meteorol., 27, 1218-1231, doi:10.1175/1520-0450(1988)027<1218:SESFRE $>2.0 . C O ; 2$

Simpson, J., R. F. Adler, and G. R. North (1988), A proposed Tropical Rainfall Measuring Mission (TRMM) satellite, Bull. Am. Meteorol. Soc., 69, 278-295, doi:10.1175/1520-0477(1988)069<0278:APTRMM>2.0. $\mathrm{CO} ; 2$.

Stano, G., T. N. Krishnamurti, T. S. V. Vijaykumar, and A. Chakraborty (2002), Hydrometeor structure of a composite monsoon depression using the TRMM radar, Tellus, Ser. A, 54, 370-381.

Trewartha, G. T. (1961), The Earths Problem Climates, 334 pp., Univ. of Wis. Press, Madison, Wis.

Zheng, Y., Y. Fu, Y. Liu, H. Zhu, Y. Xie, X. Yao, and R. Yu (2004), Heavy rainfall structures and lightning activities in a cold front cyclone happened in Huai river derived from TRMM PR and LIS observations, Acta Meteorol. Sin., 62, 790-802.

J. C. Conforte, S. H. Franchito, V. B. Rao, C. M. E. Santo, and A. C Vasques, Centro de Previsão de Tempo e Estudos Climáticos, Instituto Nacional de Pesquisas Espaciais, CP 515, São José dos Campos, SP, $12245-$ 970, Brazil. (fran@cptec.inpe.br) 